REVISTA DE DERECHO UNED, NÚM. 12, 2013

\title{
EL RETO DE LA PREVENCIÓN DEL BLANQUEO DE CAPITALES EN UN MUNDO GLOBALIZADO
}

\author{
THE CHALLENGE OF MONEY LAUNDERING PREVENTION \\ IN A GLOBAL WORLD
}

José Antonio Mateos Martín

Doctorando. Departamento de Derecho Penal y Criminología. UNED

Resumen: El blanqueo de capitales es uno de los fenómenos de mayor impacto social del mundo contemporáneo. Esta repercusión social es debida, en parte, al ruido mediático del que se hacen eco diariamente los medios de comunicación mundial y a la repercusión económica que tiene este fenómeno en las economías mundiales, minando el amplio abanico que va desde las cuentas de un Estado, hasta la moral individual de las personas, o lo que es lo mismo, afectando tanto a aspectos macroeconómicos como a los microeconómicos.

Desde que en los años 80, y unido al tráfico de estupefacientes comenzó a considerarse un problema para los Estados, el blanqueo de capitales ha sido tratado de diversas formas. En un principio se le consideró como un daño colateral, sin dotarle de la capacidad destructiva que verdaderamente tiene, siendo en los últimos veinte años cuando se le ha considerado como una verdadera amenaza para el orden económico establecido.

A partir de ese momento un enjambre de leyes, resoluciones, órdenes, instrucciones, etc, emanan de los poderes legislativos de los Estados, que viéndose superados, en muchas ocasiones por sus fronteras físicas y por las facilidades de la globalización, intentan acordar la mejor manera de combatir, con una sola voz, este fenómeno delictivo. 
Abstract: The impact of money laundering in the contemporary world is impressive. In part, media attention has contributed to this impact since world media informs on a daily basis of money laundering cases; at the same time, its economic impact plays a role in the relevance citizens put in this phenomenon. It affects the State accounts as well as the individual well-being of particular subjetcs, not to mention its macroeconomic impact.

Money laundering has been treated, together with drug traffic, since the early eighties as a problem for the individual State. At first it was considered a collateral damage, without realizing the really destructive capacity it holds. In the last twenty years its dangers have been realized and a constellation of laws, resolutions, instructions, etc, have been produced by the States. But Status are oftenly unable to fight a phenomenon that trascends fisical borders in a global world.

Palabras clave: Blanqueo de capitales, Globalización, Comisión de Prevención del Blanqueo de Capitales e Infracciones Monetarias, Blanqueo, GAFI, SEPBLAC.

Keywords: Money Laundering; Globalization; Agency for the prevention of Money Laundering; GAFI; SEPBLAC.

Recepción original: 23/05/2013

Aceptación original: 24/05/2013

Sumario: I. Introducción. II. Contextualización internacional del problema del blanqueo de capitales: evolución legislativa. III. Situación normativa administrativa y penal en España: estado actual de la cuestión. IV. Conclusiones

\section{INTRODUCCIÓN}

Según la Comisión de Prevención del Blanqueo de Capitales e Infracciones Monetarias ${ }^{1}$, se entiende por blanquear capitales como: "conjunto de mecanismos o procedimientos orientados a dar apariencia de legitimidad o legalidad a bienes o activos de origen delictivo ${ }^{2}$. El blanqueo de capitales se concibe como una figura

1 SEPBLAC, http://www.sepblac.es/español/home_esp.htm [consulta en línea 27-11-2012].

2 En la doctrina pueden leerse otras definiciones, véase por ejemplo ABEL SouTO, El delito de blanqueo en el Código penal español, 2005; ArAnguez SÁnchez, El delito de blanqueo de capitales, 2000; Blanco Cordero, El delito de blanqueo de capitales, 2012. 
delictiva propia ${ }^{3}$, aun requiriendo para su realización, además de un delito previo, una fase posterior en la que se administren los beneficios económicos, asegurándolos e introduciéndolos en el tráfico jurídico con apariencia de legalidad, como capital a todas luces legítimo ${ }^{4}$.

El terrorismo y sus ramificaciones figuran en la agenda política de la mayoría de los países por la utilización de las tipologías o técnicas de blanqueo de dinero para financiar aquellas actividades. Según los últimos datos estimados la actividad procedente del tráfico de drogas representa algo más del 15\% de la economía mundial, y parte de este dinero termina financiando actividades relacionadas con el terrorismo. Todo ello nos ofrece una visión, aunque no completa, si aproximada, de lo alarmante de esta situación que ha llevado a los Estados y organismos internacionales a poner frente común desarrollando legislaciones y medidas para prevenir el blanqueo de fondos 5 .

El blanqueo de dinero provoca efectos negativos sobre la economía, como los cambios inexplicables en la demanda de dinero, el riesgo para la solidez bancaria, el aumento de la volatilidad de los flujos de capital (hacia paraísos fiscales), el tipo de cambio debido a movimientos de capital entre países no previstos, el aumento desproporcionado en inversiones inmobiliarias, fuerte demanda de productos suntuarios, etc. El desarrollo económico, la globalización financiera $^{6}$, el intercambio en las balanzas comerciales, las facilidades en el transporte internacional, la liberalización económica, los avances tecnológicos como Internet y los mercados financieros virtuales han traído consigo un aumento considerable en la calidad de vida pero también un auge desmesurado de la criminalidad financiera.

Esta lucha contra el blanqueo de capitales, que en tiempos pasados no fue considerado un fenómeno que despertase mucha preocupación, hoy se afronta tanto a nivel nacional como internacional,

3 La Ley 10/2010, de 28 de abril, de prevención del blanqueo de capitales y de la financiación del terrorismo, ya recoge la definición blanqueo de capitales como tal, hasta ese momento la utilización del término blanqueo no fue pacífica.

4 Manjón-Cabeza Olmeda, "Receptación y blanqueo de capitales», en MoriLlas Cueva (Coord.) Sistema de Derecho penal español. Parte especial, 2011; Martos NúÑEZ, «La receptación profesional», en CPCrim, 1985; VIDALES RodRíGUEZ, Los delitos de receptación y de legitimación de capitales en el Código penal de 1995, 1997.

5 Por este motivo es comprensible que haya despertado tanto interés por su prevención en el ámbito de la Política criminal, véase en este sentido BAJO FERNÁNDEZ/ Bacigalupo sagesse (eds) Política criminal y blanqueo de capitales, 2009.

6 FABIÁN CAPARRós "El blanqueo de capitales», en El sistema penal frente a los retos de la nueva sociedad, 2003. 
ya que las organizaciones criminales en la actualidad no conocen fronteras y vienen desarrollando sus ilícitas actividades en territorio de uno o más países, favorecidos por los sistemas de comunicación, globalización, rapidez en las transacciones económicas, etc.

Hoy el blanqueo de capitales se constituye como una empresa del crimen organizado que funciona utilizando todos los mecanismos que la sociedad pone a su alcance, incluso adelantándose a esta. La globalización faculta el campo de operaciones para el blanqueo de capitales y dificulta su persecución, dando a estas organizaciones capacidad sobre el orden económico y social.

A medida que los Gobiernos han tomando conciencia de la importancia que está adquiriendo al blanqueo de fondos procedente de hechos delictivos, han ido diseñando una serie de medidas para la lucha contra el blanqueo de capitales.

\section{CONTEXTUALIZACIÓN INTERNACIONAL DEL PROBLEMA DEL BLANQUEO DE CAPITALES: EVOLUCIÓN LEGISLATIVA}

Una de las primeras iniciativas en este sentido fue la Recomendación del Comité de Ministros del Consejo de Europa, de 27 de junio de 1980, relativa a medidas contra la transferencia y encubrimiento de capitales de origen criminal, suponiendo esta iniciativa un tímido comienzo comunitario para tutelar de forma preventiva la transparencia de la actividad bancaria y combatir así la transformación de fondos producto de hechos delictivos. Las medidas de control que establecía consistían en:

- Verificación de identidad de los clientes que realicen operaciones de cierta importancia.

- Creación de una reserva de billetes con los números de serie registrados ${ }^{7}$.

- Formación del personal que trabaja en las entidades bancarias sobre el fenómeno del blanqueo.

- Colaboración policial internacional, especialmente a través de INTERPOL.

\footnotetext{
7 Esta medida iba dirigida sobre todo a supuestos de atraco o secuestro con la finalidad de poder realizar un seguimiento del delincuente a través de ellos e impedir el blanqueo de los mismos.
} 
Por tanto, en esta primera iniciativa no se recoge ninguna disposición jurídico penal, sino un estándar mínimo de medidas bancarias para combatir el blanqueo de capitales.

Posteriormente, abundando en lo establecido en la Recomendación, el Comité de Basilea sobre Regulación y Supervisión Bancaria dicta la Declaración de Principios de Basilea sobre prevención de la utilización del sistema bancario para el blanqueo de fondos de origen criminal, aprobado el 28 de diciembre de 1988, (posteriormente revisado en 2006).

Esta Declaración se circunscribía igualmente al ámbito y operativa bancaria, recogiendo una serie de reglas y prácticas destinadas a detectar y rechazar cualquier transacción bancaria sospechosa de ilegalidad. Este documento carecía de fuerza vinculante puesto que el Comité de Basilea carecía de capacidad normativa. No obstante, como declaración de principios tuvo bastante aceptación y muchos bancos adoptaron las medidas que se recomendaban en la Declaración ${ }^{8}$.

La primera norma jurídico-penal con carácter realmente vinculante fue la Convención de las Naciones Unidas contra el Tráfico Ilícito de Estupefacientes y Sustancias Psicotrópicas ${ }^{9}$ celebrada en Viena el 20 de diciembre de 1988, ratificada por España el 30 de julio de 1990 (entró en vigor en noviembre de ese año). Se trata de un instrumento de enorme importancia ya que en su elaboración participaron 106 países y actualmente forman parte del Convenio la mayoría de Estados de la Tierra.

El Convenio de Viena marcó un hito en la perspectiva internacional del blanqueo de dinero ya que por primera vez se establece en el marco interestatal una formulación minuciosa y obligatoria de un tipo penal contra el blanqueo de capitales, aunque sólo toma en consideración los delitos de tráfico de drogas, como hechos previos susceptibles de generar capitales que puedan ser objeto de delito de blanqueo, algo coherente con los objetivos y fines de la Convención.

La piedra angular del Convenio de Viena fue la de establecer para los Estados miembros la obligación de castigar con sanciones penales conductas de blanqueo de capitales relacionadas con la droga.

8 El apartado III de la Declaración se refiere al cumplimiento de las leyes, que JONCKHEERE interpreta en el sentido que «toda operación que no se muestre legalmente conforme o que viole las reglas deontológicas debe ser proscrita».

$9 \quad$ En adelante Convención de Viena de 1988. 
La «Convención de Naciones Unidas contra la delincuencia organizada transnacional» del año 2000, conocida como la Convención de Palermo, puede considerarse la continuación de la Convención de Viena de 1988 manteniéndose respecto a la penalización del blanqueo de capitales la aplicación de las medidas legislativas que sean necesarias para tipificar como delito las conductas de conversión o transferencia de bienes cometidas intencionalmente con el propósito de ocultar o disimular la verdadera naturaleza, origen, ubicación, disposición, movimiento o propiedad de bienes.

De otra parte las cuarenta recomendaciones establecidas por el GAFI constituyen el marco básico de lucha contra el blanqueo de capitales y han sido concebidas para una aplicación universal. Abarcan el sistema jurídico-penal y policial; el sistema financiero y su reglamentación; y la cooperación internacional, debiendo reconocerse como la norma idónea para la lucha contra el lavado de capitales, teniendo como objetivo operativo la labor del FMI. En su estrategia contra el blanqueo de capitales se contienen tres directrices:

- La prevención (normativa sobre controles a la circulación monetaria).

- La represión (inclusión como tipo penal).

- El comiso de los beneficios ilícitos.

Si bien su cometido expiraba a finales de agosto de 2004, la extensión de sus competencias en el año 2001 a la lucha contra la financiación del terrorismo y la introducción de nueve Recomendaciones Especiales ${ }^{10}$ en esa materia, ha motivado la renovación de su mandato hasta diciembre del año 2012.

En la actualidad forman parte del GAFI treinta y cuatro países y dos organismos internacionales. La misión del GAFI es respaldar los trabajos que llevan a cabo las organizaciones regionales similares y cooperar estrechamente con los organismos internacionales implicados en la lucha contra el blanqueo de capitales y la financiación del terrorismo; extender el mensaje de lucha contra el blanqueo de capitales y la financiación del terrorismo; supervisar la aplicación de las Recomendaciones y organizar reuniones de expertos sobre tipologías y nuevas tendencias de blanqueo de capitales.

10 En el año 2001 a raíz de los atentados del 11-S, el GAFI amplió su mandato hacia la lucha contra el terrorismo y su financiación y acordó la adopción de recomendaciones especiales sobre la financiación del terrorismo, en principio se establecieron ocho recomendaciones; en el Plenario celebrado en octubre del año 2004 se aprueba una nueva. 
La supervisión de la implantación y aplicación de las recomendaciones se lleva a cabo a través de dos procedimientos:

A) Un cuestionario de auto-evaluación anual que permite valorar el alcance de la aplicación de las recomendaciones tanto individualmente por país como por el Grupo en su conjunto.

B) Un proceso de evaluación mutua mediante el cual cada país miembro es examinado por un equipo de expertos de otros países miembros en los aspectos legales, financieros y jurídicos con el fin de evaluar los mecanismos de lucha contra el blanqueo de capitales y la financiación del terrorismo.

El GAFI reconoció, desde el principio, que los países tienen sistemas jurídicos y financieros diferentes, de modo que todos ellos no pueden adoptar las mismas medidas.

Por lo tanto, las Recomendaciones ${ }^{11}$ constituyen los principios de acción en materia de blanqueo de capitales que los países deben aplicar, de acuerdo con sus circunstancias particulares y su marco constitucional, dejando a los países cierta flexibilidad en su aplicación, en lugar de obligar a cumplir todos los detalles.

Al principio igual que en la Convención de Viena el ámbito del blanqueo de capitales se reducía a los ingresos ilícitos procedentes del tráfico de drogas, posteriormente el GAFI invita a ampliar el concepto de blanqueo a otros hechos previos considerados como delitos graves según cada legislación. Esta ampliación encontró una respuesta espectacular y el 2 de julio de 1999 el GAFI informó que todos los países excepto dos habían extendido el blanqueo a delitos graves.

La Convención de Viena sirvió de modelo para este instrumento, sus preceptos fueron tomados en consideración hasta el punto de que se trató de utilizar en la medida de lo posible la terminología y sistemática empleada por la Convención de Naciones Unidas, notándose especialmente esa influencia en la descripción de las conductas blanqueadoras.

Respecto a su contenido, no se trata de un instrumento internacional limitado al blanqueo de dinero aunque sí se ocupa por completo de los productos del delito, aclarando algunos términos («bienes» «productos», «confiscación», «delito principal»...) y las

11 Por ejemplo, la Recomendación número cinco; de acuerdo con lo previsto en la Convención de Viena, el delito del blanqueo de capitales debería aplicarse al menos a las actividades intencionales de blanqueo, entendiendo que el elemento intencional podrá inferirse de circunstancias de hecho objetivas. 
medidas a adoptar por cada país respecto al embargo, y comiso de los mismos.

Particular interés tiene el Convenio de Estrasburgo por la ampliación de los hechos previos cuyo producto es susceptible de constituir blanqueo de capitales a «todo delito penal que genere un producto», lo cual generó una discusión doctrinal debido a que en el preámbulo se hablaba de "delitos graves», resolviéndose por los expertos que el ámbito del Convenio debería ser lo más amplio posible, obligando a que el catálogo de hechos previos abarcase toda clase de delitos.

Finalmente, ante el temor de que el Convenio no alcanzara la ratificación de forma rápida, pasó a considerarse prematura la afirmación anterior y se dispuso que las partes eligiesen a través de una reserva, los hechos previos cuyos productos serían susceptibles de comiso o blanqueo de capitales, estableciéndose un «sistema a la carta de delitos base».

Como novedades a destacar del Convenio de Estrasburgo ${ }^{12}$ es que impuso el principio de universalidad desligándolo de la jurisdicción de los hechos previos y dando cierta independencia al delito de blanqueo de capitales; faculta a las partes para no aplicar el delito de blanqueo a los que intervinieron en el hecho previo (auto-encubrimiento); reconocimiento de la prueba indiciaria.

La Directiva 91/308/CEE del Consejo relativa a la prevención de la utilización del sistema financiero para el blanqueo de capitales, aprobada el 10 de junio de 1991. Su importancia radica en los efectos que produjo en Europa y en la Comunidad Internacional, pues supuso una mayor uniformidad de un estándar mínimo normativo que abarcó la prohibición del blanqueo, obligaciones de control y conservación de documentos, así como deberes de información a las autoridades de las operaciones sospechosas de blanqueo de capitales.

El artículo 16.1 de la Directiva obligaba a que los Estados miembros armonizasen sus legislaciones antes del 1 de enero de 1993, aunque finalmente se retrasó un año sobre la fecha prevista. En el caso español, motivó la reforma del Código Penal mediante Ley Orgánica 8/92, de 23 de diciembre, que supuso la modificación del artículo 344 bis relativo al blanqueo, ampliando

\footnotetext{
12 "Convenio relativo al blanqueo, seguimiento, embargo y decomiso de los productos del delito». Comité de Ministros, septiembre de 1990.
} 
los delitos previos al tráfico de drogas, delincuencia organizada y terrorismo.

La normativa comunitaria ha sido objeto de las varias modificaciones a lo largo del tiempo y motivada por el devenir de acontecimientos y avances tecnológicos:

Directiva 2001/97/CEE del Parlamento Europeo y del Consejo, de 4 de diciembre de 2001, por la que se modifica la Directiva 91/308/ CEE del Consejo relativa a la prevención de la utilización del sistema financiero para el blanqueo de capitales, con fecha límite de transposición el 15 de junio de 2003. Dictada con la finalidad de seguir garantizando un elevado grado de protección del sector financiero y de otras actividades vulnerables frente a los efectos perjudiciales de las actividades delictivas. Ampliación del ámbito de los delitos subyacentes a cualquier tipo de participación delictiva en la comisión de un delito grave.

Ampliación del ámbito de sujetos obligados, incluyendo a auditores, contables externos y asesores fiscales.

Los notarios y los profesionales independientes del ámbito jurídico deben estar sujetos a lo dispuesto en la Directiva cuando participen en operaciones financieras, empresariales o inmobiliarias, incluido el asesoramiento fiscal, en las que exista el mayor riesgo de que se empleen indebidamente a fin de blanquear el producto de actividades delictivas.

Directiva 2005/60/CE, del Parlamento Europeo y del Consejo de 26 de octubre de 2005, relativa a la prevención de la utilización del sistema financiero para el blanqueo de capitales y para la financiación del terrorismo.

Esta Directiva hace referencia al asesoramiento profesional en el sentido de que el asesoramiento jurídico sigue sujeto a la obligación de secreto profesional, salvo en caso de que el abogado esté implicado en actividades de blanqueo de capitales o financiación del terrorismo; que la finalidad del asesoramiento jurídico sea el blanqueo de capitales o la financiación del terrorismo, o de que el abogado sepa que el cliente solicita asesoramiento jurídico para fines de blanqueo de capitales o financiación del terrorismo.

El nuevo texto introduce disposiciones detalladas sobre la exigencia de identificación del cliente y del titular real. Los Estados miembros tuvieron hasta el 15 de Diciembre de 2007 para su transposición. Esta tercera Directiva sobre blanqueo de capitales deroga la Directiva 91/308/CE. 
Directiva 2006/70/CE ${ }^{13}$ de la Comisión, de 1 de agosto de 2006, por la que se establecen disposiciones de aplicación de la Directiva 2005/60/CE del Parlamento Europeo y del Consejo en lo relativo a la definición de "personas del medio político» y los criterios técnicos aplicables en los procedimientos simplificados de diligencia debida con respecto al cliente así como en lo que atañe a la exención por razones de actividad financiera ocasional o muy limitada.

Un resumen de la legislación a nivel internacional sería, a grandes rasgos y cronológicamente, el siguiente:

- Recomendación de 27 de junio de 1980, del Comité de Ministros del Consejo de Europa, relativa a medidas contra la transferencia y el encubrimiento de capitales de origen criminal. En esta Recomendación se considera que la transferencia de capitales de origen criminal de un país a otro y su blanqueo mediante la introducción en el circuito financiero, suscita graves problemas, favorece la comisión de nuevos delitos y se propaga el fenómeno tanto nacional como internacionalmente.

- Convención de las Naciones Unidas contra el Tráfico Ilícito de Estupefacientes y Sustancias Psicotrópicas, aprobado en Viena el 19 de diciembre de 1988. Da la primera definición sobre el blanqueo de capitales y cita medidas penales para que sean adoptadas por los Estados para luchar contra el blanqueo. Aunque solo reconoce el fenómeno parcialmente, al tomar como causa única el tráfico de drogas.

- Declaración de Basilea, aprobada el 28 de diciembre de 1988, por el Comité de Basilea, sobre Regulación y Supervisión Bancaria. Señala procedimientos y reglas que servirán para colaborar en la lucha contra operaciones de blanqueo de dinero a través del sistema bancario, tanto nacional como internacionalmente.

- Informe del Grupo de Acción Financiera Internacional (GAFI), en París, el 6 de febrero de 1990, con 40 recomendaciones para prevenir el blanqueo de capitales. Entre ellas, aconseja

13 Esta directiva hace una muy interesante definición, y de rabiosa actualidad, de las «PEP» personas políticamente expuestas, definiendo conceptos incluidos en la directiva 2006/60/CE. Detalla en qué ocasiones será posible aplicar los «procedimientos simplificados de diligencia debida» en el caso de autoridades $u$ organismos públicos que presenten un riesgo bajo de blanqueo. Este extremo es de interesante estudio a tenor de los acontecimientos de casos de corrupción política que derivan en blanqueo de capitales. 
que todos los países ratifiquen y apliquen el Convenio de Viena, tipificando como delito grave el blanqueo de capitales, y adoptando medidas para el decomiso de los bienes objeto del blanqueo, los productos de los mismos, los instrumentos utilizados y todos aquellos cuyo origen provenga del blanqueo.

- Convenio del Consejo de Europa sobre Blanqueo, Identificación, Embargo y Comiso de los productos del Delito, de 8 de noviembre de 1990. Este Convenio insta a los Estados miembros a promover medidas legislativas para favorecer las investigaciones de blanqueo de capitales, así como, la fiscalización de los productos procedentes del blanqueo. Propone la adopción de medios suficientes para la lucha contra el blanqueo y la obligación de prestarse auxilio entre Estados miembros.

- Directiva del Consejo de la Comunidad Europea (91/308/ CEE), de 10 de junio de 1991, relativa a la prevención de la utilización del sistema financiero para el blanqueo de capitales. Indica la necesidad de que el blanqueo de capitales se combata con medidas penales y en el marco de la colaboración internacional. Amplia el catálogo de causas y consecuencias de afectación del blanqueo, además del trafico de drogas, al terrorismo y a la delincuencia organizada.

- Convención de las Naciones Unidas contra la delincuencia organizada transnacional, celebrada en Palermo en diciembre de 2000. Propone medidas de combate y penalización del blanqueo de dinero procedente de delitos como el narcotráfico.

- Directiva del Consejo de las Comunidades Europeas (2001/97/ CEE), del Parlamento Europeo y del Consejo, de 4 de diciembre de 2001, relativa a la prevención de la utilización del sistema financiero para el blanqueo de capitales. Esta directiva amplia el blanqueo de capitales al blanqueo de los productos procedentes de la participación delictiva en delitos graves.

- Convención de las Naciones Unidas contra la corrupción, celebrada en Mérida, (México, 2003). Realiza un planteamiento del blanqueo de dinero, del secreto bancario y de la inteligencia financiera.

- Directiva 2005/60/CE, del parlamento Europeo y del Consejo, de 26 de octubre de 2005, relativa a la prevención de la utilización del sistema financiero para el blanqueo de capitales y la 
financiación del terrorismo. Esta Directiva actualiza el marco jurídico del blanqueo de capitales e incluye explícitamente la financiación del terrorismo en la definición de lavado de dinero.

- Directiva 2006/70/CE, del la Comisión, de 1 de agosto de 2006. Se establecen disposiciones de aplicación de la Directiva anterior (2005/60/CE) en lo relativo a definición de "personas del medio político» y los criterios técnicos aplicables en los procedimientos simplificados de diligencia debida con respecto al cliente, y en lo que atañe a la exención por razones de actividad financiera ocasional o muy limitada.

En abril de 2012, la Comisión Europea anunció la aprobación de la cuarta Directiva sobre blanqueo de capitales (la tercera Directiva es la 2005/60/CE), con la aprobación de la propuesta legislativa en el próximo otoño-invierno. El título del mismo comunicado de prensa ya es significativo de la importancia del problema en el seno de la Unión "Contra el blanqueo de dinero: creando un marco europeo moderno y capaz de responder a las nuevas amenazas» ${ }^{14}$. La Comisión reconoce que los riesgos asociados al blanqueo de dinero están en constante evolución lo cual exige una revisión periódica del marco legal, por ello tras el análisis del informe sobre la tercera Directiva, aprobado esa misma primavera de 2012, se pretenden subsanar las deficiencias y ponerse al día en cuanto a la lucha contra el blanqueo. Todo ello encaminado a la unificación futura de una legislación que luche contra el blanqueo de capitales ${ }^{15}$.

\section{SITUACIÓN NORMATIVA ADMINISTRATIVA Y PENAL EN ESPAÑA: ESTADO ACTUAL DE LA CUESTIÓN}

La legislación española, penal y administrativa, ha ido incorporando paulatinamente las «recomendaciones y obligaciones» establecidas por las iniciativas internacionales citadas en el apartado anterior, a las que se ha ido adhiriendo ${ }^{16}$.

14 CONTROLCAPITAL.NET, http://www.controlcapital.net/noticia/1273/ANTILAVADO/La-UE-aprueba-el-informe-de-revision-de-la-tercera-directiva-sobre-elblanqueo-de-capitales-y-anuncia-la-cuarta-directiva-para-otono-8064-lecturas.html

15 Explicando todo lo anterior con detenimiento, Aranguez Sánchez, El delito de blanqueo de capitales, cit.; Blanco Cordero, El delito de blanqueo de capitales, cit.

16 También aquí existen muchos escritos. Una visión general muy interesante es la que ofrece Carpio Delgado, El delito de blanqueo de bienes en el nuevo Código penal, 1997. 
En el campo del derecho administrativo estas «recomendaciones y obligaciones» quedaron reflejadas en la Ley 19/1993, de 28 de diciembre, sobre determinadas medidas de prevención del blanqueo de capitales y su Reglamento de desarrollo, Real Decreto 925/1995, de 9 de junio, normativa que para adaptarse a las modificaciones de armonización impuestas por Europa sufrió diferentes modificaciones:

A. Ley 19/1993, de 28 de diciembre, sobre determinadas medidas de prevención del blanqueo de capitales ${ }^{17}$. Las obligaciones de esta ley fueron desarrolladas reglamentariamente por el Real Decreto $925 / 1995$, de 9 de junio. A destacar:

- Esta norma se dirige no solo a las personas y entidades que integran el sistema financiero sino también a otras actividades susceptibles de ser utilizadas para el blanqueo de capitales.

- Establece la obligación de comunicar las operaciones que muestren una falta de correspondencia ostensible con la naturaleza, volumen de la actividad o antecedentes operativos de los clientes, siempre que en su examen no se aprecie justificación económica, profesional o de negocio para la realización de las operaciones.

- Impone la obligación a quienes deben cumplir la ley de contar con procedimientos y órganos internos para la prevención del blanqueo de capitales.

- Exige a las entidades españolas que establezcan en sus sucursales y filiales en el extranjero procedimientos internos de prevención del blanqueo de capitales.

- Establece un cuadro sancionador común a los distintos tipos de entidades financieras sujetas al cumplimiento de esta ley.

- Regula la Comisión de Prevención del Blanqueo de Capitales e Infracciones Monetarias y su Servicio Ejecutivo.

B. Ley Orgánica 10/1995, de 23 de noviembre, por la que se aprueba el Código Penal, modificada por la Ley Orgánica 15/2003, de 25 de noviembre. Tipifica el blanqueo de capitales como un delito de receptación especial, aplicándolo a las ganancias provenientes de cualquier delito grave ${ }^{18}$.

17 Modificada por: Ley 44/2002, de 22 diciembre (art. 16.2); Ley 12/2003, de 21 de mayo (art. 15.2.g); Ley 19/2003, de 4 de julio (Art. 1.1; art. 2.2, 3 y 4; art. 3.1, 2, 4, 7 y 9; art. 5.2; art. 8.3; art. 12; art. 16.1; Disposición adicional segunda.); Ley 36/2006, de 29 de noviembre (art. 2.1).- Derogada por Ley 10/2010, de 28 de abril.

18 Véase sobre nuestra legislación Martínez-Buján PÉrez, Derecho penal económico y de la empresa. Parte especial, 3. a ed. 2011; SERrano Gómez/SERrano Maíllo, 
C. Ley 19/2003, de 4 de julio, sobre régimen jurídico de los movimientos de capitales y de las transacciones económicas con el exterior y sobre determinadas medidas de prevención del blanqueo de capitales ${ }^{19}$. Destacando que:

- Esta ley establece el principio de libertad de los movimientos de capitales en línea con el Tratado Constitutivo de la Comunidad Europea y lo que ha de entenderse por transacciones económicas con el exterior.

- Define los conceptos de residente y no residente en España ${ }^{20}$.

- Posibilita el conocimiento de los movimientos de capitales y transacciones económicas con el exterior a través de un mecanismo de declaración, se identifican los sujetos obligados a declarar y los destinatarios de la información.

- Establece la posibilidad de realizar actos y negocios afectados por cláusulas de salvaguardia ${ }^{21}$ o medidas excepcionales a través de autorización administrativa.

- Los órganos de la Comisión de Prevención del Blanqueo de Capitales e Infracciones Monetarias (Servicio Ejecutivo y Secretaría) llevarán a cabo a requerimiento del instructor del procedimiento sancionador por infracciones contra el régimen jurídico de movimiento de capitales, o por propia inicia-

Derecho penal. Parte especial, 16. ${ }^{a}$ edición, 2011; SERrano TÁrRaga, en SERrano GóMEZ y otros, Derecho penal. Parte especial, 2012.

19 Modifica a: Ley 40/1979, de 10 de diciembre Transpone a: Directiva del Consejo de 10 de junio (DIR 91/308/CEE), modificada por la Directiva 2001/97/CE del Parlamento Europeo y del Consejo de 4 de diciembre de 2001. Modifica a: Ley 19/1993, de 28 de diciembre (arts. 1.1; 2.2,3 y 4; 3.1,2,4,7 y 9; 5.2;8.3;12;16.1; y Disposición adicional segunda) Ley 230/1963, de 28 de diciembre General Tributaria (art. 112.5 y 113.1 j); Ley 13/1985, de 25 de mayo (Disposición adicional segunda); Ley 46/2002, de 18 de diciembre (Disposición adicional cuarta); Ley 51/2002, de 27 de diciembre (Disposición adicional decimotercera). Deroga: Ley 19/1993 de 28 de diciembre (art. 13.1 párrafo segundo); Ley 40/1979, de 10 de diciembre (En su totalidad, salvo Capítulo II); Ley 41/1999, de 12 de noviembre (Disposición adicional cuarta).

20 «Residentes»: Las personas físicas que residan habitualmente en España. Las personas jurídicas con domicilio social en España. «No residentes»: Las personas físicas que tengan su residencia habitual en territorio extranjero, y las personas jurídicas con domicilio social en el extranjero.

21 Se entenderá prohibida o limitada, en los términos que señalen las normas comunitarias, la realización de determinados movimientos de capitales y sus correspondientes operaciones de cobro o pago, así como las transferencias de o al exterior o las variaciones en cuentas o posiciones financieras deudoras o acreedoras frente al exterior, respecto de terceros países en relación con los cuales el Consejo de la Unión Europea, de conformidad con lo establecido en el artículo 59 del Tratado Constitutivo de la Comunidad Europea, haya adoptado medidas de salvaguardia. 
tiva, las actuaciones de investigación que resulten adecuadas para el esclarecimiento de los hechos que pudieran ser constitutivas de las infracciones tipificadas en esta ley.

- Clasifica las infracciones en materia de movimientos de capitales, en muy graves, graves y leves, y establece sus correspondientes sanciones.

- Mejora los instrumentos de control sobre el efectivo y otros medios de pago para reducir el riesgo de blanqueo de capitales y financiación del terrorismo ${ }^{22}$.

D. Real Decreto 54/2005, de 21 de enero, por el que se modifican el reglamento de la Ley 19/1993, de 28 de diciembre, sobre determinadas medidas de prevención del blanqueo de capitales, aprobado por el Real Decreto 925/1995, de 9 de junio, y otras normas de regulación del sistema bancario, financiero y asegurador. A destacar:

- El Reglamento amplía la obligación de comunicar operaciones sospechosas a auditores, contables externos o asesores fiscales, notarios, abogados y procuradores.

- Extiende las obligaciones a las actividades de transporte profesional de fondos o medios de pago, a las actividades de giro o transferencia internacional realizadas por los servicios postales y la comercialización de loterías u otros juegos de azar respecto de las operaciones de pago de premios.

- Introduce la obligación de presentar declaración previa sobre el origen, destino y tenencia de fondos para la salida o entrada en territorio nacional de fondos por importe superior a $6.000 €$ y para los movimientos por territorio nacional de medios de pago superiores a los $80.500 €$ (actualmente $10.000 €$ y $100.000 €$ respectivamente $)^{23}$.

- Establece que los sujetos obligados deberán adoptar medidas para comprobar razonablemente la veracidad de la actividad profesional o empresarial de sus clientes.

- Como novedad se establece la posibilidad de cursar las comunicaciones sospechosas en forma electrónica. Para ello el Servicio Ejecutivo establecerá procedimientos técnicos que

22 Blanco Cordero, El delito de blanqueo de capitales, cit.

23 Orden EHA/1439/2006, de 3 de mayo, reguladora de la declaración de movimientos de medios de pago en el ámbito de la prevención del blanqueo de capitales, eleva las cuantías sujetas a declaración: 10.000 euros para la entrada o salida por frontera y en 100.000 euros para los movimientos por territorio nacional. 
garantice la confidencialidad del contenido de las comunicaciones.

- Los procedimientos de control interno y de comunicación que deben de establecer los sujetos obligados tendrán que ser objeto de examen anual por un experto externo.

- En cuanto al régimen sancionador añade como novedad que la omisión de declaración o la falta de veracidad de los datos declarados, siempre que pueda estimarse como especialmente relevante, determinará la intervención por las Fuerzas y Cuerpos de Seguridad del Estado o del Departamento de Aduanas e Impuestos Especiales de la totalidad de todos los medios de pago hallados. En la creación de nuevas entidades financieras se introduce como nuevo requisito el contar con procedimientos y órganos de control para impedir la realización de operaciones relacionadas con el blanqueo de capitales ${ }^{24}$.

E. Diversas Órdenes ministeriales:

- Orden ECO/2652/2002, de 24 de octubre, por la que se desarrollan las obligaciones de comunicación de operaciones, en relación con determinados países, al Servicio Ejecutivo de la Comisión de Prevención del Blanqueo de Capitales e Infracciones Monetarias. Se actualiza la lista de países o territorios no cooperantes identificados por el GAFI.

- Orden EHA/2963/2005, de 20 de septiembre, reguladora del Órgano Centralizado de Prevención en materia de blanqueo de capitales en el Consejo General del Notariado. Regula el (OCP) Órgano Centralizado de Prevención, que debe establecer el Consejo General del Notariado para reforzar y canalizar la colaboración de los notarios con la autoridades en materia de blanqueo de capitales.

- Orden EHA/1439/2006, de 3 de mayo, reguladora de la declaración de movimientos de medios de pago en el ámbito de la prevención de blanqueo de capitales. Establece las cantidades de dinero sujetas a declaración tanto para la salida o entrada por frontera, como para los movimientos por territorio nacional. Regula la obligación de las entidades de crédito de comunicar al SEPBLAC las operaciones que por sus características están sujetas a la declaración del modelo S1.

24 Blanco Cordero, El delito de blanqueo de capitales, cit. 
- Orden EHA/2619/2006, de 28 de julio, por la que se desarrollan determinadas obligaciones de prevención del blanqueo de capitales de los sujetos obligados que realicen actividades de cambio de moneda o gestión de transferencias con el exterior. Regula las operaciones que no sean objeto de cargo o abono en cuenta del cliente que las realiza, establece criterios de identificación del cliente, regula la conservación de documentos por período de seis años.

- Orden EHA/2444/2007, de 31 de julio, por la que se desarrolla el Reglamento de la Ley 19/1993, de 28 de diciembre, sobre determinadas medidas de prevención del blanqueo de capitales, aprobado por Real Decreto 925/1995, de 9 de junio, en relación con el informe externo sobre los procedimientos y órganos de control interno y comunicación establecidos para prevenir el blanqueo de capitales.

- Orden EHA/114/2008, de 29 de enero, reguladora del cumplimiento de determinadas obligaciones de los notarios en el ámbito de la prevención del blanqueo de capitales. Imponen, a los notarios, la obligación de identificar a los clientes, conservar los documentos y procedimientos de control y evaluación, además de comunicar a las autoridades competentes la coincidencia, en su caso, de la identidad de los otorgantes con las de las personas y entidades contenidas en los listados de derecho comunitario.

En fecha 30 de abril del año 2010 entró en vigor la nueva Ley 10/2010, de 28 de abril ${ }^{25}$, de Prevención del Blanqueo de Capitales y de la Financiación del Terrorismo, con un claro intento de unificar la doctrina legal recogida hasta ahora en nuestro país en la Ley 19/1993, de 28 de diciembre, sobre determinadas medidas de prevención del blanqueo de capitales, Ley 19/2003, de 4 de julio, sobre régimen jurídico de los movimientos de capitales y de las transacciones económicas con el exterior y la Ley 12/2003, de 21 de mayo, de bloqueo de la financiación del terrorismo, denominaciones de estas dos últimas leyes que son modificadas por la disposición final primera y segunda, respectivamente, de la ley 10/2010. Ésta Ley también modifica a la Ley 35/2003, de 4 de noviembre, de instituciones de inversión colectiva. Como apuntes más destacados:

25 Hasta la entrada en vigor de las disposiciones reglamentarias de la Ley 10/2010 de 28 de abril, mantenía su vigencia el Reglamento de desarrollo de la Ley 19/1993, de 28 de diciembre, sobre determinadas medidas de prevención del blanqueo de capitales, Real Decreto 925/1995, de 9 de junio. 
- Transpone la Directiva 2005/60/CE del Parlamento Europeo y del Consejo, de 26 de octubre de 2005, relativa a la prevención de la utilización del sistema financiero para el blanqueo de capitales y para la financiación del terrorismo, desarrollada por la Directiva 2006/70/CE de la Comisión, de 1 de agosto de 2006, del Parlamento Europeo ${ }^{26}$.

- Esta Ley unifica los regímenes de prevención del blanqueo de capitales y de la financiación del terrorismo, adaptando la sistemática propia a la prevista en las Directivas Europeas.

- Regula las obligaciones, las actuaciones y procedimientos para prevenir e impedir la utilización del sistema financiero, así como de otros sectores de actividad económica, para el blanqueo de capitales procedentes de cualquier tipo de participación en la comisión de un delito.

- Establece la obligación de comunicar las operaciones que presenten indicios de estar relacionadas con el blanqueo de capitales o la financiación del terrorismo. Asimismo, regula la obligación de comunicación sistemática de operaciones al Servicio Ejecutivo.

- Impone la obligación a quienes deben cumplir la Ley de contar con procedimientos y órganos internos para la prevención del blanqueo de capitales.

- Exige a las entidades españolas que establezcan en sus sucursales y filiales en el extranjero procedimientos internos de prevención del blanqueo de capitales, estableciendo un cuadro sancionador común a los distintos tipos de sujetos obligados.

- Regula la Comisión de Prevención del Blanqueo de Capitales e Infracciones Monetarias y su Servicio Ejecutivo.

En lo referente al campo de lo penal, al ámbito represivo de los actos de blanqueo de capitales, se enumeran las reformas del Código Penal que han supuesto la incorporación de la normativa internacional y comunitaria a la legislación nacional.

La Reforma del Código Penal del 73, por la Ley Orgánica 1/1988, de 24 de marzo, incorporó el delito de blanqueo de capitales provenientes del tráfico de estupefacientes castigando, las acciones de

\footnotetext{
26 Página oficial de la Comisión de Prevención de Blanqueo de Capitales e Infracciones Monetarias (Sepblac), http://www.sepblac.es/espanol/legislacion/prevbcap/ fichas/ley10_10.htm. [consultada en línea 21-03-2013]
} 
recibir, adquirir o aprovecharse de cualquier modo, para sí o para un tercero, de los efectos o ganancias de éste tráfico.

La Reforma del Código Penal, por la Ley Orgánica 8/1992, de 23 de diciembre, tipificó el blanqueo de capitales tal y como fue definido por la Convención de Viena, pero aplicado exclusivamente a las ganancias obtenidas del tráfico de estupefacientes y sustancias psicotrópicas, terrorismo y crimen organizado.

El Código Penal aprobado por Ley Orgánica 10/1995, de 23 de noviembre, dando cumplimiento a la Directiva 91/308/CE, tipifica en los artículos 301 a 304 el blanqueo de capitales como un delito de receptación especial, aplicándolo no sólo a las ganancias del tráfico ilegal de drogas, sino también a las provenientes de cualquier delito grave.

La posterior reforma del nuevo texto de 1995, por la Ley Orgánica 15/2003, de 25 de noviembre, amplía los artículos $301^{27}$ y 302, eliminando la necesidad de la consideración de «delito grave», permitiendo el decomiso de las ganancias obtenidas por el culpable y, en casos de delito de tráfico de drogas o pertenencia a organización dedicada al blanqueo, el comiso de los bienes objeto del delito y de los productos y beneficios obtenidos.

La modificación del Código Penal operada por Ley Orgánica 5/2010, de 22 de junio (en vigor desde el 23 de noviembre de 2010), establece importantes novedades, toda vez que esta nueva modificación ha sido introducida tras la Ley 10/2010, de 28 de abril, de Prevención del Blanqueo de Capitales y de la Financiación del Terrorismo. De esta modificación podemos destacar ${ }^{28}$ :

- El artículo 301 del Código Penal contempla el delito de blanqueo de capitales con las conductas de «adquirir, utilizar, convertir o transmitir bienes, sabiendo que éstos tienen su origen en una actividad delictiva». Tras la reforma se introduce una nueva conducta, la de «poseer o utilizar» dichos bienes.

- De otra parte, y muy interesante, es la Ley 10/2010, de 28 de abril, sobre Prevención del Blanqueo de Capitales, la que nos indica qué es lo que se entiende por bienes procedentes de

27 Texto anterior: «1. El que adquiera, convierta o transmita bienes, sabiendo que éstos tienen su origen en un delito grave, o realice cualquier otro acto para ocultar o encubrir su origen ilícito, o para ayudar a la persona que haya participado en la infracción o infracciones a eludir las consecuencias legales de sus actos, será castigado con la pena de prisión de seis meses a seis años y multa del tanto al triplo del valor de los bienes»

28 Revista Inteligencia, número del primer trimestre 2012, págs. 30-33. 
una actividad delictiva, entre dichos bienes se incluye la cuota defraudada en el caso del delito contra la Hacienda Pública, esto es, según el artículo 305 del Código Penal defraudar más de $120.000 €$. Por lo que defraudar más de esta cantidad se considera por la Ley de Prevención del Blanqueo de Capitales como bien procedente de actividad delictiva. Contrastando lo mencionado sacamos las siguiente conclusiones:

- Que la simple posesión de la cuota defraudada a Hacienda, supone un delito de blanqueo de capitales.

- Que al introducir al tipo penal del Blanqueo de Capitales la conducta de "poseer», el citado tipo penal se convierte en un delito de tipo continuado, es decir, mientras se posea la cuota, se está cometiendo el delito. Por todo lo cual la prescripción del delito de blanqueo de capitales (que es de 10 años atendiendo al Código Penal) empezara a computar una vez se ingrese la cuota defraudada.

- Por todo lo cual y como conclusión podría decirse que el delito de blanqueo de capitales no prescribirá nunca, pues la simple tenencia constituye un acto ilícito. Al ser el blanqueo de capitales un delito conexo que va siempre ligado al delito previo (en este caso el delito fiscal), hasta que no se regularice la situación tributaria no comenzará a computar al plazo de prescripción de 10 años (art. $131 \mathrm{CP}$ ) lo cual no implica que el Ministerio Fiscal no pueda iniciar un procedimiento penal de oficio pues en el artículo 305.4 del C.P., nada se dice de la exención de responsabilidad respecto al delito de blanqueo de capitales.

Reforma del Código Penal por Ley Orgánica 7/2012, de 27 de diciembre (vigente desde el 17 de enero de 2013), en materia de transparencia y lucha contra el fraude fiscal y en la Seguridad Social. Esta reforma está inspirada en criterios de mejora de la eficacia de los instrumentos de control de los ingresos y del gasto público, aprobando las reformas necesarias en los sectores económicos afectados por la crisis. A destacar de las modificaciones en su articulado:

- Incluye a los partidos políticos y sindicatos dentro del régimen general de responsabilidad, suprimiendo la referencia contenida en el apartado 5 del artículo 31 bis, por lo que se les exigirá responsabilidad por las actuaciones ilícitas desarrolladas por su cuenta y en su beneficio, por sus representantes legales y administradores, o por los sometidos a la autoridad 
de los anteriores cuando no haya existido un control adecuado sobre los mismos.

- Se permite a la Administración Tributaria continuar con el procedimiento administrativo de cobro de la deuda tributaria a pesar de pender un procedimiento penal.

- La cuantía de la cuota tributaria defraudada en el ámbito de los ingresos de la Hacienda de la Unión Europea se determinará por relación al año natural.

- Se introduce una regla especial en tramas de criminalidad organizada para poder actuar de forma inmediata cuando la defraudación supere la cuantía mínima del delito (120.000 €).

- Se introduce la atenuación de la pena cuando los presuntos responsables de los delitos reconozcan su comisión y satisfagan íntegramente la deuda tributaria.

- Para tipificar conductas de mayor gravedad se introduce un tipo agravado llevando la pena máxima hasta los seis años, elevando el plazo de prescripción a diez años evitando así la impunidad por el paso del tiempo. Se consideran supuestos agravados, cuando la cuantía de la cuota defraudada supere los seiscientos mil euros, cuando la defraudación se cometa en el seno de una organización o grupo criminal, o aquéllos en los que la utilización de personas, negocios, instrumentos o territorios dificulte la determinación de la identidad o patrimonio del verdadero obligado tributario o responsable del delito o cuantía defraudada.

- En los casos en los que la defraudación supere los cuatro mil euros y no exceda de cincuenta mil son castigados como delitos, desapareciendo la hasta ahora tipificación por falta.

- Se armoniza la penalidad impuesta a las personas jurídicas responsables con la prevista para las personas físicas por los mismos hechos; se introduce la pena del multa del doble al cuádruple en los supuestos agravados; del mismo modo se prevé la imposición a la personas jurídicas responsables de estos delitos de la pena de inhabilitación para obtener subvenciones y ayudas públicas para contratar con el sector público y para gozar de beneficios en incentivos fiscales o de la Seguridad Social, por un plazo que no podrá exceder de quince años.

- En cuanto a la Seguridad Social, se reduce a cincuenta mil euros la cuantía que establece el tipo como condición objetiva 
de punibilidad, no excluyendo la mera presentación de documentos de cotización, la defraudación si ésta se acredita por otros hechos.

- Se introduce un tipo agravado por el montante de la cuantía eludida u otras circunstancias concurrentes, ampliándose la pena máxima a seis años y el periodo de prescripción a diez años ${ }^{29}$.

En la situación de crisis que se padece a nivel mundial, crisis que padecemos en nuestro país, si cabe, de una forma más virulenta debido a la flaqueza del andamio que sostiene nuestra economía, basada principalmente en la construcción, se promulga la Ley 7/2012, de 29 de octubre, de modificación de la normativa tributaria y presupuestaria y de adecuación de la normativa financiera para la intensificación de las actuaciones en la prevención y lucha contra el fraude. Ésta pretende ser la herramienta adecuada de la lucha frontal contra el fraude y la evasión fiscal.

En este contexto de crisis económica, es necesario reducir el déficit del Estado como premisa para favorecer el saneamiento de las cuentas públicas y permitir la recuperación económica, basada, principalmente en la inversión privada, lo cual ha de llevar a la creación de empleo y a la generación de crecimiento.

Esta norma ha entrado en vigor el pasado 1 de noviembre y supone, junto con la comentada más arriba Ley Orgánica 7/2012, de 27 de diciembre (vigente desde el 17 de enero de 2013), las principales normas que refuerzan las actuaciones de prevención contra el fraude fiscal, una de las prioridades de la política económica, de hecho supone el mayor esfuerzo normativo en la lucha contra el fraude y la economía sumergida. Combina medidas novedosas diseñadas para impactar directamente en nichos tradicionales de fraude fiscal, con otras que refuerzan la seguridad jurídica del sistema tributario y potencian la recaudación. Se pueden destacar las siguientes medidas:

- Obligación de información sobre bienes y derechos situados en el extranjero. Se introduce en la Ley General Tributaria (LGT) una nueva Disposición Adicional Decimoctava, pasando a ser obligatorio suministrar a la Administración Tributaria la siguiente información:

29 Abel Souto, El delito de blanqueo en el Código penal español, cit.; Aranguez SÁnchez, El delito de blanqueo de capitales, cit.; Blanco Cordero, El delito de blanqueo de capitales, cit.; CARPIO DELGado, El delito de blanqueo de bienes en el nuevo Código penal, cit.; Palma Herrera, Los delitos de blanqueo de capitales, 2000; DíazMaroto y Villarejo, El blanqueo de capitales en el Derecho español, 1999. 
- Información sobre las cuentas situadas en el extranjero abiertas en entidades que se dediquen al tráfico bancario o crediticio de las que sean titulares o beneficiarios o en las que figuren como autorizados o de alguna otra forma ostenten poder de disposición.

- Información de cualesquiera títulos, activos, valores o derechos representativos del capital social, fondos propios o patrimonio de todo tipo de entidades, o de la cesión a terceros de capitales propios, de los que sean titulares y que se encuentren depositados o situados en el extranjero, así como de los seguros de vida o invalidez de los que sean tomadores y de las rentas vitalicias o temporales de las que sean beneficiarios como consecuencia de la entrega de un capital en dinero, bienes muebles o inmuebles, contratados con entidades establecidas en el extranjero.

- Información sobre bienes inmuebles y derechos sobre bienes inmuebles de su titularidad situados en el extranjero.

- Las obligaciones antedichas se extenderán, también a quienes tengan la consideración de titulares reales de acuerdo con lo previsto en el apartado 2 del artículo 4 de la Ley 10/2010, de 28 de abril, de prevención del blanqueo de capitales y de la financiación del terrorismo.

- Se establece un nuevo marco de infracciones tributarias, siendo constitutivo de infracciones graves, el no presentar en plazo y presentar de forma incompleta, inexacta o con datos falsos esta declaración informativa o su presentación por medios distintos a los electrónicos, informáticos y telemáticos en aquellos supuestos en que hubiera obligación de hacerlo por dichos medios.

- El artículo 7 de la Ley, tipifica un nuevo tipo infractor al disponer, en su apartado Uno.1 «No podrán pagarse en efectivo las operaciones, en las que alguna de las partes actúe en calidad de empresario o profesional, con un importe igual o superior a 2.500 euros o su contravalor en moneda extranjera». Notas características de esta infracción son:

- La limitación se establece para los pagos en efectivo correspondientes a operaciones con importe igual o superior a 2.500 euros, siempre y cuando alguna de las partes actúe como empresario o profesional. Este importe se eleva a 15.000 euros si el pagador es una persona física que no ac- 
túa como empresario o profesional y sin domicilio fiscal en España. Esta limitación no es aplicable a los pagos e ingresos realizados en entidades de crédito.

- El incumplimiento de las anteriores infracciones constituyen infracción administrativa grave. Se considera sujeto infractor tanto al que pague como al que reciba, ambos responden solidariamente de la infracción cometida, la cual prescribirá a los cinco años a contar desde su comisión.

- La base de la sanción será la cuantía pagada en efectivo en las operaciones de importe igual o superior a 2.500 ó 15.000 euros, siendo la sanción en multa pecuniaria proporcional del $25 \%$. La sanción también prescribe a los cinco años a contar desde el día siguiente a aquél en que adquiera firmeza la resolución por la que se impone.

- Se exime de responsabilidad por infracción al participante en la operación que denuncie la misma ante la Agencia Tributaria dentro de los tres meses siguientes al pago, identificando a la otra parte.

- Se incluyen una serie de medidas encaminadas a reforzar la capacidad recaudatoria de la Agencia Tributaria, sobre todo en aquellos casos en los que el contribuyente intenta escapar de sus obligaciones fiscales retrasando el pago de la cuota, interponiendo obstáculos o diluyendo el patrimonio.

- Se elimina la posibilidad de aplazamientos o fraccionamientos de créditos en las situaciones de concurso para evitar la postergación artificiosa del crédito público.

- Se introduce un nuevo supuesto de responsabilidad subsidiaria contra los administradores de empresas carentes de patrimonio, pero con actividad económica.

- La norma tiene vocación de reducir al máximo el fraude del IVA, con medidas como:

- Exclusión del régimen de módulos afectará también al IVA además del IRPF.

- Se establece la inversión del sujeto pasivo en los supuestos de renuncia a la exención del IVA vinculada a ciertas operaciones inmobiliarias, así, el sujeto adquiriente solo podrá deducirse el IVA soportado si acredita que ha ingresado el IVA repercutido. De este modo se evita el doble perjuicio para la Hacienda Pública por falta de ingreso del impuesto 
por el transmitente del inmueble y por la deducción del IVA soportado.

- En los casos de declaración de concurso, el derecho a la deducción de las cuotas soportadas por el IVA con anterioridad a dicha declaración no podrá ejercitarse en liquidaciones posteriores.

- La norma modifica también el embargo de bienes y derechos en entidades de crédito para que éste se pueda extender más allá de la oficina o sucursal a la que se remitió el embargo. Asimismo, se prohíbe la disposición de inmuebles de sociedades en donde han sido embargadas acciones equivalentes a más de la mitad del capital social.

- Respecto a las medidas cautelares, se modifica el precepto para permitir su adopción en cualquier momento del procedimiento cuando así se estime oportuno. Se permite a la Agencia Tributaria adoptar las medidas cautelares en los procesos penales. También se modifica al alza la garantía que es necesario depositar para que se suspenda la ejecución de un acto impugnado, a fin de que éste cubra todos los recargos que pudieran ser exigibles.

- Se endurecen las sanciones por resistencia, obstrucción, excusas o negativa a las actuaciones inspectoras. Las sanciones oscilarán entre un mínimo de 1.000 euros y un máximo de 100.000 euros.

\section{CONCLUSIONES}

Es de sentido común que la lucha contra el fraude fiscal, y la persecución del blanqueo de capitales asociado a éste u otro tipo de delitos, no debiera acometerse a partir de diferentes organismos o instituciones que ataquen, por partes, dicho fenómeno en el ámbito de las competencias que les son propias, sino que debe ser objeto de una persecución más integrada, con equipos multidisciplinares.

En este sentido, la contemplación unitaria de la delincuencia fiscal hace imprescindible la creación de un organismo multidisciplinar que, bajo la dependencia funcional de la Agencia Estatal de la Administración Tributaria, integre, entre otros, funcionarios de la Inspección de Hacienda, del Servicio Ejecutivo de la Comisión de Prevención del Blanqueo de Capitales e Infracciones Monetarias, de los Cuerpos y Fuerzas de Seguridad del Estado y del Ministerio 
Fiscal. Un organismo de tal naturaleza estaría en condiciones de abordar con garantías de éxito la lucha contra las grandes tramas de fraude que tan relevantes perjuicios causan al conjunto de los ciudadanos al tiempo que constituiría un órgano especializado de apoyo y colaboración permanente con los órganos del Poder Judicial. La Oficina Nacional Antifraude se crearía a partir de la existente Oficina Nacional de Investigación del Fraude (ONIF), ampliando sus competencias y su despliegue territorial.

Por otro lado, la regulación española del delito de blanqueo de capitales está considerada por diferentes organismos internacionales relacionados con el mismo como una de las legislaciones más avanzadas en este aspecto y se va adhiriendo a todas las iniciativas internacionales que surgen en este sentido (Acuerdos internacionales, GAFI, Grupo Egmont, etc.). La normativa en relación con la prevención ha ido evolucionando a la par que los avances de la delincuencia en general, y en particular los avances tecnológicos que facilitan la comisión del delito.

En cuanto a la represión, la tipificación del delito es correcta, su interpretación se ha ido perfilando y asentando ciertos principios por los Tribunales en la aplicación del tipo penal recogido en los artículos 301 y siguientes:

- Se configura el blanqueo como un delito autónomo, a pesar de compartir características de la receptación y el encubrimiento.

- El delito precedente exigido ha pasado a ser cualquiera que de origen a los bienes que se intenten blanquear.

- Aplicación extraterritorial de la ley española en relación con este delito, no afectando la inimputabilidad de quien cometa el delito precedente.

- Consolidación de la prueba indiciaria.

- Admisión del blanqueo de bienes sustitutivos.

- Posibilidad de aplicar el delito de blanqueo de capitales al autor del delito precedente.

- Tras las últimas reformas legislativas se admite el fraude fiscal como delito previo del blanqueo de capitales. 
- Posibilidad de apreciación de la conducta típica por imprudencia y de forma dolosa, siendo suficiente en éste último supuesto con el dolo eventual ${ }^{30}$.

En cuanto a lo que podríamos denominar persecución o investigación del delito de blanqueo de capitales, cada vez hay más conciencia de su importancia y han aumentado tanto los medios disponibles como la formación de las personas encargadas de la persecución de este delito, pero en este campo todavía queda bastante camino por recorrer y los avances son más lentos, pese al esfuerzo que realizan las personas que se dedican a ello.

Otras medidas que pudieran resultar eficaces para la lucha contra el blanqueo de capitales, mientras llega la ansiada armonización de las legislaciones de los países de la UE (esperemos que la próxima, Cuarta Directiva, ponga la simiente en este sentido), sería el establecimiento de medidas preventivas para luchar contra delitos relacionados y que no son estrictamente blanqueo de capitales, como por ejemplo los relacionados con la evasión fiscal o infracciones contra la hacienda pública. Para ello sería idónea la utilización del conocimiento adquirido con el cruce de información entre la Administración Tributaria y el SEPBLAC.

Con relación a la Ley 10/2010 de prevención del blanqueo de capitales y la financiación del terrorismo, sería interesante que la regulación de ambas materias se hiciese por separado porque la ilicitud del blanqueo de capitales esta en el origen delictivo de los bienes que se quieren blanquear, mientras que en el caso del terrorismo lo ilícito es la utilización que se les da a esos bienes para llevar a cabo actos terroristas, pudiendo éstos tener su origen en actividades lícitas.

Las organizaciones criminales son cada vez más especializadas y con ello, la investigación también se complica ${ }^{31}$. Convierten la actividad delictiva en una empresa, en un negocio que tiene sucursales

30 Abel Souto, El delito de blanqueo en el Código penal español, cit.; Aranguez SÁNCHEz, El delito de blanqueo de capitales, cit.; Blanco CORDERo, El delito de blanqueo de capitales, cit.; CARPIO Delgado, El delito de blanqueo de bienes en el nuevo Código penal, cit.; Palma Herrera, Los delitos de blanqueo de capitales, cit.; Díaz-Maroto Y ViLlarejo, El blanqueo de capitales en el Derecho español, cit.

31 Por ese motivo a veces las organizaciones contratan los servicios de profesionales del mundo jurídico, que también pueden incurrir en responsabilidades, $\mathrm{CHO}$ CLÁN Montalvo, «Blanqueo de capitales y retribuciones a los abogados: el pago de honorarios con cargo al patrimonio presuntamente criminal», en $L L P, 2008$; CÓRDOBA Roda, Abogacía, secreto profesional y blanqueo de capitales, 2006; FARALdo CABANA, «Los autores de delito de blanqueo de bienes en el Código penal español de 1995. Especial alusión a los proveedores de bienes y/o servicios: el caso de los abogados y asesores fiscales», en Anuario de Derecho Penal y Ciencias Penales, 2006. 
en diferentes países, que importan y exportan mercancías (droga, personas etc.), tienen ramificaciones en la política y sus dirigentes adquieren reconocimiento social por las ingentes cantidades de dinero que manejan y el lujo en el que viven.

No hay que olvidar, los efectos negativos que tiene la introducción de beneficios ilícitos en el sistema financiero legal utilizando sociedades ya que se pone en peligro la libre competencia sobre la que se basa el sistema de economía de libre mercado, y con ello el orden socioeconómico.

La competencia que se realiza de este modo es una competencia desleal, en la medida en que el blanqueador alcanza una posición de privilegio respecto a sus competidores y además, de manera indirecta, puede producir alteraciones en el sistema financiero ya que los blanqueadores, cuando invierten sus ganancias ilícitas, no se comportan conforme a criterios de racionalidad económica, no buscan el máximo rendimiento, sino el lugar o la inversión que les permita lavar de forma más fácil su dinero, incluso si ello supone que recibirán un rendimiento bajo.

En cuanto a los métodos de blanqueo de capitales en los que se utilizan personas jurídicas, la delincuencia dedicada al blanqueo de capitales no cesa de buscar nuevas vías destinadas a dar apariencia de legalidad a los bienes obtenidos de forma ilícita, lo que provoca que quienes se dedican a su investigación tienen que tener suficiente amplitud de miras para descubrir las nuevas formas de blanquear que continuamente van surgiendo.

Algunas medidas que podrían mejorar la lucha contra el blanqueo de capitales mediante utilización de personas jurídicas:

- Elaborar un plan especial de identificación, de personas físicas y jurídicas que puedan ser utilizadas como testaferros para ocultar la verdadera identidad de los titulares de rentas y bienes.

- Detección preventiva de sociedades pantalla e instrumentales, mediante la investigación o establecimiento de normas de control de los llamados «nidos o nichos de sociedades». Podría servir como base el registro y comunicación obligatoria que se lleva a cabo actualmente por establecimientos de hospedería a las Fuerzas y Cuerpos de Seguridad.

- Control e investigación de personas que de forma sistemática figuren como administradores de más de un número determinado de sociedades. 
- Tipificar como un nuevo delito en el código penal la conducta consistente en el ofrecimiento al mercado de servicios idóneos para la defraudación tributaria o el blanqueo de capitales.

En cuanto a la utilización de paraísos fiscales, lo fácil sería prohibir los movimientos de capitales entre estos territorios y España, pero el Tratado de la Unión Europea no lo permite ${ }^{32}$, por lo que algunas de las medidas que se podrían tomar para paliar su utilización para la constitución de sociedades y movimientos de capitales de origen delictivo podrían ser las siguientes:

- Medidas de declaración, justificación y gravamen especial sobre movimientos de fondos con origen o destino a paraísos fiscales (regular como hecho imponible que todo movimiento de fondos, que tenga como origen o destino un paraíso fiscal tribute en España. Esto último ya está en marcha con la obligación de declarar todo el patrimonio y movimientos, aunque se encuentren o se hayan realizado fuera de España)

- No reconocer personalidad jurídica a las sociedades constituidas en paraísos fiscales para intervenir en el tráfico mercantil español salvo plena identificación de los socios.

- Inversión en medios humanos y materiales dedicados a la persecución de este delito, con una formación adecuada de sus miembros dentro de equipos multidisciplinares.

- Establecer un gravamen especial para aquellos movimientos de capitales con origen o destino en paraísos fiscales. Con establecimiento también de una penalidad agravada cuando esos movimientos tengan como finalidad un delito de blanqueo de capitales o un delito fiscal.

- No permitir que las entidades financieras españolas establezcan sucursales o filiales en paraísos fiscales.

En el ámbito internacional, una de las medidas más importantes sería el establecimiento de acuerdos con los centros financieros extraterritoriales de terceros países que garanticen una cooperación judicial eficaz y elaboración de normas dirigidas a evitar la utilización de empresas y entidades registradas fuera de la jurisdicción de la Unión Europea para ocultar los beneficios de origen delictivo,

32 Artículo 56 del Tratado Constitutivo de la Unión Europea prohíbe las restricciones a los movimientos de capitales y a los pagos entre Estados miembros, y también entre estos y terceros países. Este principio rige sobre cualquier otro. 
paliando así los inconvenientes de la existencia de paraísos fiscales o jurisdicciones «offshore».

La tendencia observada en los últimos años, tanto en lo concerniente a la responsabilidad penal de las personas jurídicas, como en el aspecto del blanqueo de capitales, ha sido la de ir adecuando la legislación española y sobre todo la europea a la importancia que para los estados ha ido adquiriendo tanto el blanqueo de capitales como la proliferación de personas jurídicas destinadas a tal fin, y es de esperar que en el futuro se siga trabajando en ese sentido, buscando un ajuste acorde con la importancia del delito y los efectos que éste produce en el sistema financiero legal.

Mención especial merece la corrupción de la clase política, con sus tejes y manejes, con sus cuentas en suiza y otros paraísos fisca$\operatorname{les}^{33}$ con sus componendas, con sus actuaciones muy alejadas de la moralidad requerida en un servidor público, por sus desparpajos, mintiendo y desmintiendo cuando hablan de sus implicaciones en casos de tráfico de influencias, de prevaricación y de sobornos en sus diferentes modalidades.

En todas las clases y tipología de funcionarios públicos, no hemos de olvidar que los políticos también lo son, (al menos en cuanto a las funciones que tienen encomendadas) existe un «régimen disciplinario» amén del código deontológico de conducta, moral y ético como servidores públicos.

En España tenemos algunos (más de los que pensábamos) componentes de la casta política, que carecen de las ultimas virtudes mencionadas y que son incapaces de asumir sus actos dimitiendo en sus puestos de trabajo al servicio del ciudadano y colaborando para clarificar, lo antes posible, las acusaciones o desviaciones de lo exigido como servidor público. Estas actuaciones están contribuyendo a crear un malestar en la ciudadanía, y siguiendo un camino opuesto a lo que se demanda de una persona que se erige como representante de los ciudadanos.

Visto lo dicho y sabiéndolos incapaces de practicar una política digna, con asunción de responsabilidades, sería interesante la constitución de un órgano colegiado que bien podría llamarse «Régimen Disciplinario Político», formado por (por ejemplo), abogados del estado, jueces y magistrados, notarios, registradores de la propie-

33 Solo tenemos que echar un vistazo a cualquier diario y cualquier día de la semana, en éstos aparecen políticos de todos los colores implicados en diferentes tipologías delictivas, todas ellas relacionadas con el dinero. 
dad, etc., en resumen, altos funcionarios del estado, los cuales serian elegidos de forma análoga a como se vienen eligiendo los tribunales del jurado, y cuyo mandato fuese por 3 años. O sea, un Régimen Disciplinario compuesto por un número de 15 miembros (número impar para evitar empates), renovado por tercios cada 3 años y cuya función seria «encausar» las conductas políticas que conozcan y que estén inmersas en alguna de las conductas citadas más arriba.

Se trata de poder «valorar» las conductas de todas las personas con cargos políticos y que falten a su deber como políticos. Estas conductas no serían las penales, que para eso ya están los tribunales, sino las relacionadas con la ética política. Las resoluciones emanadas del Régimen Disciplinario serían de obligatorio cumplimiento y lo probado en aquel podría ser utilizado por los juzgados y tribunales posteriormente, si se llega al enjuiciamiento.

Este Régimen tendría, en pro del principio de legalidad, un catálogo de conductas merecedoras de sus actuaciones, en las que por supuesto deberían de estar aquellas en las que se descubre que un político tiene capitales (dinero, inmuebles, etc.) que se escapan del control estatal o de difícil explicación teniendo en cuenta el sueldo que devengan. Sin duda, que cualquier encausamiento de este Régimen Disciplinario, sería suficiente para apartar al político de su cargo, al menos preventivamente, obligándole a dimitir en cuanto se pueda dar veracidad a alguna de las conductas incluidas en ese "catálogo de conductas». Las cantidades «encontradas» en cuentas, empresa o cualquier otro lugar, que sean imputadas al político serán intervenidas $\mathrm{y}$, si finalmente se demuestra cualquier conducta indigna y que figure en el mencionado catálogo, serán adjudicadas a un fondo creado al efecto y que todos los años será publicada su finalidad en el «Boletín Oficial del Estado». 
